\title{
Analysis of genes involved in response to doxorubicin and a GD2 ganglioside-specific 14G2a monoclonal antibody in IMR-32 human neuroblastoma cells*
}

\author{
Irena Horwacik1凶 Małgorzata Durbas, Elżbieta Boratyn¹, Anna Sawicka1\#, Paulina Węgrzyn², \\ Sylwia Krzanik1', Anna Górka1', Joanna Drożniak1, Ewa Augustyniak1, Aleksandra Kowalczyk¹ \\ and Hanna Rokita'
}

'Laboratory of Molecular Genetics and Virology, ²Department of Cellular Biochemistry, Faculty of Biochemistry, Biophysics and Biotechnology,

The Jagiellonian University, Kraków, Poland

\begin{abstract}
Neuroblastoma is the most common extra-cranial solid tumor of childhood and it is characterized by the presence of a glycosphingolipid, GD2 ganglioside. Monoclonal antibodies targeting the antigen are currently tested in clinical trials. Additionally, several research groups reported results revealing that ganglioside-specific antibodies can affect cellular signaling and cause direct cytotoxicity against tumor cells. To shed more light on gene expression signatures of tumor cells, we used microarrays to analyze changes of transcriptome in IMR-32 human neuroblastoma cell cultures treated with doxorubicin (DOX) or a mouse monoclonal antibody binding to GD2 ganglioside 14G2a (mAb) for $24 \mathrm{~h}$. The obtained results highlight that disparate cellular pathways are regulated by doxorubicin and 14G2a. Next, we used RT-PCR to verify mRNA levels of selected DOX-responsive genes such as RPS27L, PPM1D, SESN1, CDKN1A, TNFSF10B, and 14G2a-responsive genes such as SVIL, JUN, RASSF6, TLX2, ID1. Then, we applied western blot and analyzed levels of RPS27L, PPM1D, sestrin 1 proteins after DOX-treatment. Additionally, we aimed to measure effects of doxorubicin and topotecan (TPT) and 14G2a on expression of a novel human NDUFAF2 gene encoding for mimitin protein (MYC-induced mitochondrial protein) and correlate it with expression of the $M Y C N$ gene. We showed that expression of both genes was concomitantly decreased in the 14G2a-treated IMR-32 cells after $24 \mathrm{~h}$ and $48 \mathrm{~h}$. Our results extend knowledge on gene expression profiles after application of DOX and 14G2a in our model and reveal promising candidates for further research aimed at finding novel anti-neuroblastoma targets.
\end{abstract}

Key words: doxorubicin, GD2 ganglioside, microarray, 14G2a, neuroblastoma, mimitin

Received: 13 March, 2015; revised: 20 April, 2015; accepted: 20 May, 2015; available on-line: 18 August, 2015

\section{INTRODUCTION}

Neuroblastoma is the most common extra-cranial solid tumor diagnosed in childhood and the disease shows a remarkable biological heterogeneity (Øra \& Eggert, 2011). Hence, a high rate of spontaneous regressions can be observed in infants with the $4 \mathrm{~S}$ stage of the disease (Brodeur \& Bagatell, 2014). On the contrary, an improvement of outcomes of patients with high risk neuroblastoma still remains a major challenge for pediatric on- cologists (Moreno et al., 2013). Neuroblastoma cells are marked with presence of GD2 ganglioside and tests of passive administration of monoclonal antibodies targeting the tumor-associated antigen are clinically advanced. Recently, $\mathrm{Yu}$ et al., reported that addition of a chimeric monoclonal antibody ch14.18 binding GD2 ganglioside, IL-2, and GM-CSF to 13-cis retinoic acid is effective in children with high risk neuroblastoma (Yu et al., 2010).

Several research reports establish clearly that binding of ganglioside-specific antibodies can affect fate of cancer cells, e.g., lead to changes in cellular signaling and induce cell death that may encompass apoptosis, necrosis, and oncosis-like mechanisms (for review on the topic see Horwacik \& Rokita, 2015). In 2009, our group showed that a mouse monoclonal antibody $(\mathrm{mAb})$ 14G2a caused cell death with partial involvement of apoptosis in cultures of a human neuroblastoma cell line IMR-32, as evidenced by a rise in staining with Annexin $\mathrm{V}$ and propidium iodide and an increase in caspase 3 activity (Kowalczyk et al., 2009). Moreover, synergistic effects were observed when 14G2a was combined with standard chemotherapeutic drugs such as doxorubicin (DOX) that is an anthracycline antibiotic blocking activity of topoisomerase II, and topotecan (TPT) that is a camptothecan analogue and an inhibitor of topoisomerase I (Kowalczyk et al., 2009).

Biology of neuroblastoma is being intensively studied. MYCN amplification is an independent negative prognostic factor in neuroblastoma. Additionally, high expression levels of aurora A kinase were shown to indicate a shorter survival in neuroblastoma patients (Ramani et al., 2015). In 2013, our group showed that aurora A and MYCN oncogenic proteins are decreased upon the 14G2a-treatment of IMR-32, which correlated with an increase of a tumor suppressor protein P53. Moreover, the antibody enhanced effects of an aurora A inhibitor, $\mathrm{MK}-5108$, and 13-cis retinoic acid in some MYCN-am-

e-mail: irena.horwacik@uj.edu.pl

* Preliminary report on the same subject has been presented during the 42nd Winter School of Faculty of Biochemistry, Biophysics and Biotechnology, Zakopane 10-14 February 2015

\#Present address: Anna Sawicka, Ph.D., Department of Molecular Biology, Max Planck Institute for Biophysical Chemistry, Am Faßberg 11, 37077 Göttingen, Germany

Abbreviations: ANOVA, analysis of variance; DOX, doxorubicin; FDR, false discovery rate; GD2, GD2 ganglioside; GO, gene ontology; mAb, monoclonal antibody; RT-PCR, Reverse Transcription Polymerase Chain Reaction; qt-RT-PCR, quantitative Reverse Transcription Polymerase Chain Reaction; TPT, topotecan 
plified neuroblastoma cell lines (Horwacik et al., 2013). This fuels our efforts to characterize more deeply effects of the 14G2a mAb on survival of the tumor cells. Therefore, primarily we focused our experiments to decipher changes in expression of genes in IMR-32 cells treated with 14G2a using microarrays. Also, we aimed to compare the changes of transcriptome in 14G2atreated cells to doxorubicin-treated cells. Previously, the chemotherapeutic drug had been shown by us to act synergistically with 14G2a on IMR-32 cells (Kowalczyk et al., 2009). Then, based on the microarray results, we intended to analyze expression of selected 14G2a- and doxorubicin-responsive genes by RT-PCR and western blot techniques. Finally, we wanted to analyze changes in expression of NDUFAF2 upon addition of $14 \mathrm{G} 2 \mathrm{a}$, doxorubicin or topotecan to IMR-32 cells.

Here, we present result of microarray analyses of changes in transcriptome of IMR-32 cells treated with 14G2a or DOX for $24 \mathrm{~h}$. Gene ontology (GO) analysis showed that genes regulated by DOX are involved in such cellular processes as induction and positive regulation of cell death (including apoptosis), DNA metabolic processes, negative regulation of cell proliferation, and response to UV. This contrasts with genes regulated by $14 \mathrm{G} 2 \mathrm{a}$ which were assigned to a single group of genes involved in regulation of RNA metabolic processes. Although the results generated with microarrays had showed rather limited changes in mRNA profiles, they allowed us to select new gene candidates for further research. Thus, expression patterns of some selected genes: RPS27L, PPM1D, SESN1, CDKN1A, TNFSF10B, SVIL, JUN, RASSF6, TLX2, ID1 were analyzed in our model by application of RT-PCR and/or western blot techniques. Also, we showed a correlation between changes of expression of a NDUFAF2 gene encoding for mimitin (MYC-induced mitochondrial protein) and the MYCN gene in the 14G2a-treated IMR-32 cells. The performed experiments allowed us to gain more insight into gene regulation in IMR-32 cells after treatment with 14G2a and DOX. Literature search on 14G2a-responsive genes allowed us to conclude that on one side the antibody affects pathways already established as important for neuroblastoma biology, on the other side novel gene candidates can be selected for further analyses.

\section{MATERIALS AND METHODS}

Cell culture and treatment with doxorubicin and 14G2a mAb. Cell culture of IMR-32 (ATCC, USA, CCL-127), KELLY (Leibniz-Institut DSMZ - Deutsche Sammlung von Mikroorganismen und Zellkulturen GmbH, Germany, ACC 355), both MYCN-amplified human neuroblastoma cells, a MYCN-non-amplified SKN-SH human neuroblastoma cells (ATCC, HTB-11), a hybridoma cell line producing the 14G2a mAb (kindly provided by Dr. R. Reisfeld, The Scripps Research Institute, La Jolla, CA, USA), purification of the 14G2a $\mathrm{mAb}$, treatment of IMR-32 cells with doxorubicin, topotecan, and 14G2a were previously described in details (Horwacik et al., 2013; Kowalczyk et al., 2009). For most of the experiments IMR-32 cells were used. Briefly, IMR-32 cells were grown in EMEM containing 1\% nonessential amino acid solution, $1 \mathrm{mM}$ sodium pyruvate, 50 $\mu \mathrm{g} / \mathrm{ml}$ of gentamicin (all from Sigma-Aldrich, Poland), supplemented with $10 \%$ fetal calf serum (Life Technologies, Poland) at $37^{\circ} \mathrm{C}$, and in an atmosphere containing $5 \% \mathrm{CO}_{2}$. The cells were treated with doxorubicin, $14 \mathrm{G} 2 \mathrm{a} \mathrm{mAb}$, or both agents for a given time (see the
Results). Control cells were also included in experiments. The concentration of doxorubicin was $15 \mathrm{nM}$ for microarray studies, $15 \mathrm{nM}, 17 \mathrm{nM}$ and $30 \mathrm{nM}$ for RT-PCR and western blot studies (see the Results). The 14G2a $\mathrm{mAb}$ was used at concentration of $40 \mu \mathrm{g} / \mathrm{ml}$ for all results presented below. In some experiments cells were treated with $2 \mathrm{nM}$ topotecan. The effects of the drugs on the IMR-32 cells were measured using cell viability tests, i.e., MTT tests (Sigma-Aldrich) or ATPlite Luminescence ATP Detection Assay System (Perkin Elmer, USA) according to instructions from manufacturers.

Microarray hybridization. Microarray hybridization was performed by Genbioinfo (Krakow, Poland). Total RNA was isolated using the TRIZOL reagent according to the manufacturer's instructions (Invitrogen, Carlsbad, CA). RNA concentration was measured using a ND-1000 Spectrometer (NanoDrop Technologies Inc., Montchanin, DE, USA). RNA quality was determined using an Agilent Bioanalyzer 2100 (Agilent, Palo Alto, CA, USA). A starting amount of $200 \mathrm{ng}$ of high-quality total RNA was used to generate cDNA and cRNA with the Illumina TotalPrep RNA Amplification Kit (Illumina, San Diego, CA, USA). The procedure consisted of RT with an oligo(dT) primer bearing a $\mathrm{T} 7$ promoter using Array-Script. The obtained cDNA became a template for in vitro transcription with T7 RNA polymerase and biotin UTP, which generated multiple copies of biotinylated cRNA. The purity and concentration of the cRNA were determined using a NanoDrop ND-1000 Spectrometer. Quality cRNA was subsequently hybridized using a direct hybridization array kit (Illumina). Each cRNA sample $(1.5 \mu \mathrm{g})$ was hybridized overnight using the $\mathrm{Hu}-$ manHT-12 BeadChip array (Illumina) in a multiple-step procedure; the chips were washed, dried, and scanned on the BeadArray Reader (Illumina). Raw microarray data were generated using BeadStudio v3.0 (Illumina). A total of 12 Illumina HumanHT-12v3 microarrays were used in the experiment.

Microarray data analysis. Microarray data analysis was performed by Genbioinfo (as shown on data presented on Fig. 1, Table 1-3). Microarray analysis and quality control of the arrays were performed using BeadArray R package v1.0.0. After background subtraction (using median background method), the data were normalized using quintile normalization and were subsequently $\log _{2}$-transformed. The obtained signal was taken as the measure of mRNA abundance derived from the level of gene (or particular transcriptional form) expression. The following criteria were applied for probe-set detection: at least three samples with signal intensity $>7.4$ (log2 data). This reduced the number on the analyzed probes to 19642 (from total 49895). Two-Way ANOVA was applied to calculate significance levels ( $\mathrm{P}$ values) to discriminate differentially expressed genes between controls and the treated groups. The false discovery rate (FDR) was estimated using the Benjamini and Hochberg method. All statistical analyses were performed using $\mathrm{R}$ software version 2.10.1. Hierarchical clustering was performed with dChip software using Euclidean distance and average linkage method. The Database for Annotation, Visualization and Integrated Discovery (DAVID 2.1), a functional annotation analysis tool, was used to identify over-represented ontological groups among gene expression profiles and to group genes into functional classifications (with default options).

Determination of levels of selected transcripts with RT-PCR. RNA isolation, cDNA production from DOX-, TPT-, 14G2a-treated and control cells were performed as described previously (Horwacik et al., 2013; 
Kowalczyk et al., 2009). From 1 to $4 \mu \mathrm{g}$ of total RNA was used in reactions with reverse transcriptase. $M Y C N$ primers were from Stock et al. (Stock et al., 2008), ACTB primers were from Kowalczyk et al. (Kowalczyk et al., 2005), EF2-1 primers were from Skalniak et al. (Skalniak et al., 2014), MYC primers were from Wang et al. (Wang et al., 2008). Other primers were designed using Primer-BLAST (http://www.ncbi.nlm.nih.gov/tools/primerblast/) or Primer3web version 4.0.0 software (Koressaar and Remm, 2007; Untergrasser et al., 2012, http://primer3.sourceforge.net) and their annealing temperatures were optimized empirically (sequences of primers from 5' to 3', product sizes of amplicons, and annealing temperatures of primers are listed below): For semiquantitative RT-PCR following primers were used: CDKN1 A-1 (F:CTGCCCAAGCTCTACCTTCC, R: CAGGTCCACATGGTCTTCCT, product size $123 \mathrm{bp}$, annealing temp. $57^{\circ} \mathrm{C}$ ), RPS27L (F: TGCCGAGCGCAGATCGCTTG, R: TGGCCTTTCCTCCTGTAGGCTGG, product size $294 \mathrm{bp}$, annealing temp. 61 ${ }^{\circ} \mathrm{C}$ ), SESN1 (F: CTTCTGGAGGCAGTTCAAGC, R: TGAATGGCAGCCTGTCTTCAC, product size $341 \mathrm{bp}$, annealing temp. $59^{\circ} \mathrm{C}$ ), TNFRSF10B (F: GGCCCCACAACAAAAGAGGTCCA, R: CCCCAGGTCGTTGTGAGCTTCTG, product size $599 \mathrm{bp}$, annealing temp. $\left.65^{\circ} \mathrm{C}\right), P P M 1 D$ (F: TTCTCGCTTGTCACCTTGCC, R: CCAAACTACACGATTCACCCC, product size 302, annealing temp. $59^{\circ} \mathrm{C}$ ), MYC (F: TCAAGAGGCGAACACACAAC, R: GGCCTTTTCATTGTTTTCCA, product size $110 \mathrm{bp}$, annealing temp. $57^{\circ} \mathrm{C}$ ). For normalization of amounts of samples, cDNA of $A C T B$ was measured using primers ACTB (F: AGCGGGAAATCGTGCGTG, R: GGGTACATGGTGGTGCCG, product size $307 \mathrm{bp}$, annealing temp. $\left.55^{\circ} \mathrm{C}\right)$. Primers used for qtRT-PCR were as follows: NDUFAF2 (F: GCAGGGGATATTCCAACAGA, R: GCAGGAGTTCCTCACTGGTC, product size 173 bp, annealing temp. $55^{\circ} \mathrm{C}$ ), MYCN (F: ACCACAAGGCCCTCAGTACCT, R: GTGGTGACAGCCTTGGTGTTG, product size $144 \mathrm{bp}$, annealing temp. $\left.60^{\circ} \mathrm{C}\right)$, ID1 (F: TCAGCACCCTCAACGGCGAGAT, CCAGGTACCCGCAAGGATGGGA, product size $150 \mathrm{bp}$, annealing temp. $62^{\circ} \mathrm{C}$ ), SVIL (F: GGTGTGGAAGAGCCGGGTAGA, R: AGTCCTCAAGGCCATCCACTTGAA, product size $149 \mathrm{bp}$, annealing temp. $62^{\circ} \mathrm{C}$ ), CDKN1 $A-2$ (F: CAGCTGCTGCAACCACAGGGATTT, R: CATCACAGTCGCGGCTCAGCT, product size $146 \mathrm{bp}$, annealing temp. $62{ }^{\circ} \mathrm{C}$ ), RASSF4 (F: TAAGACCTCCGTGTTTACTCCA, R: GATGTAGAGTGCGAACTCACTG, product size $150 \mathrm{bp}$, annealing temp. $60^{\circ} \mathrm{C}$ ), JUN (F: TCCAAGTGCCGAAAAAGGAAG, R: CGAGTTCTGAGCTTTCAAGGT, product size $156 \mathrm{bp}$, annealing temp. $60^{\circ} \mathrm{C}$ ), TLX2 (F: TGAGGGGCTCTAGCGGCGTT, R: AATCAGCCAGCCTCTCGCGC, product size $115 \mathrm{bp}$, annealing temp. $60^{\circ} \mathrm{C}$ ). EF2-1 (F: GACATCACCAAGGGTGTGCAG, R: TCAGCACACTGGCATAGAGGC, product size $214 \mathrm{bp}$, annealing temp. $62^{\circ} \mathrm{C}$ ), or EF2-2 primers (F: GGTGCAGTGCATCATCGAGGAGTC, R: TCGCGGTACGAGACGACCGG, $144 \mathrm{bp}$, annealing temp. $62^{\circ} \mathrm{C}$ ) were used to measure reference cDNA.

Western blotting analyses of protein expression. Whole cell protein extracts were prepared, resolved using SDS/PAGE, and expression levels of particular proteins were determined using a western blot technique as described previously in details (Kowalczyk et al., 2009; Horwacik et al., 2013). For detection and quantification of particular proteins we optimized empirically: methods of isolation of proteins, amounts of cellular proteins and particular antibodies used for western blotting. Fol- lowing primary antibodies were used: rabbit polyclonal anti-sestrin 1 antibodies (1:10000 dilution, SAB1401644, Sigma-Aldrich), and rabbit polyclonal anti-RPS27L antibodies (1:3000 dilution, SAB4502097, Sigma-Aldrich), a mouse monoclonal anti-GAPDH antibody (G-8795, 30000-40000 times diluted, dilution, Sigma-Aldrich), a mouse monoclonal anti-PPM1D (WIP1) antibody (WH0008493M1, 0.167-1.0 $\mu \mathrm{g} / \mathrm{ml}$, Sigma-Aldrich), goat anti-mimitin polyclonal antibodies (sc:50098, 1:200 dilution, Santa Cruz Biotechnology, USA), rabbit polyclonal anti-MYCN antibodies (sc: 791, 1:200 dilution, Santa Cruz Biotechnology), a mouse anti-c-MYC monoclonal antibody (sc:42, 1:200 dilution, Santa Cruz Biotechnology), and anti- $\alpha$-tubulin antibody (\#2125S; 1:1000 dilution; Cell Signaling, USA). Secondary HRP conjugate antibodies used were as follows: goat anti-rabbit IgG polyclonal antibodies (A-0545, 10000-20000 times diluted, Sigma-Aldrich), rabbit anti-mouse IgG antibodies (A-9044, 20000-40000 times diluted, Sigma-Aldrich), rabbit anti-goat IgG antibodies (A-5420, 1:20000, SigmaAldrich), and goat anti-rabbit IgG (\#7074, 1:2000, Cell Signaling). Samples were normalized using reference signal from binding of the anti-GAPDH or anti- $\alpha$ tubulin antibodies.

Statistical analyses. Data on graphs on Figs 3-5 are shown as means with SEM (standard errors of the means). Statistical significance between signals of controls and drug-treated samples were analyzed using pairwise $t$ tests (Excel, Microsoft Office). For analysis of time-dependence of signals on the graphs presented on the Fig. 4 and the Fig. 5, we applied one-way ANOVA with repeats using $\mathrm{R}$ software ( $\mathrm{R}$ version 2.15.1 Patched), $* P<0.05$, $* * P<0.01$, *** $P<0.001$.

\section{RESULTS}

\section{Microarray analyses of IMR-32 cells treated with DOX and $14 \mathrm{G} 2 \mathrm{a}$}

We performed research to extend our knowledge on mechanism involved in cell death upon binding of the 14G2a mAb to neuroblastoma cells. We used microarray technology to decipher changes in expression of genes in the model of MYCN-amplified IMR-32 cells treated with $14 \mathrm{G} 2 \mathrm{a} \mathrm{mAb}$, and compared them to a standard chemotherapeutic drug, doxorubicin. 12 sets of Illumina HT-12v3 microarrays were used to analyze 3 independent experiments consisting of control cells, and cells treated for $24 \mathrm{~h}$ with $15 \mathrm{nM}$ doxorubicin, $40 \mu \mathrm{g} / \mathrm{ml}$ of $14 \mathrm{G} 2 \mathrm{a}$, and both agents. Data analyses were performed on 19642 probes from a total number of 49895 probes. The list of probes, obtained with ANOVA at FDR $<5 \%$, showing response to doxorubicin contains 46 positions (see Table 1 for the list and Fig. 1A that shows a hierarchical clustering of the doxorubicin-responsive genes and particular transcriptional forms). The list of transcripts affected by 14G2a contains 28 positions (see Table 2 for the list and Fig. 1B that shows a hierarchical clustering of 14G2a-responive genes or particular transcriptional forms, ANOVA at FDR $<5 \%$ ). For the probes changed after treatment with DOX we measured increase of signal in the range from about 1.1-2.8 as compared to control cells. Particularly, an increase of $\geq 1.5$ was measured for: CDKN1A, ACTA2, RN7SK, SESN1, TNFSF10B, RPS27L, BAX, PHLDA3, GADD45 and 2 sequences HS.545589 and HS.193406 (see Table 1). For the rest of probes changes between 1.5 and 1.1 were observed. Additionally, out of 46 probes only 9 were down-regulated 
Table 1. Transcripts responsive to treatment with doxorubicin*

\begin{tabular}{|c|c|c|c|c|}
\hline Probe ID & NCBI accession no. & Gene ID & Gene name & Fold change $e^{* *}$ \\
\hline 4230201 & NM_000389.2 & 1026 & CDKN1A & 2.8 \\
\hline 6480059 & NM_001613.1 & 59 & $A C T A 2$ & 2.0 \\
\hline 2640719 & $N R_{=} 001445.1$ & 125050 & $R N 7 S K$ & .1 .8 \\
\hline 990176 & $\mathrm{NR}=001445.1$ & 125050 & RNTSK & 1.8 \\
\hline 1660437 & U62823 & & HS. 545589 & 1.7 \\
\hline 1240553 & $N M_{2}=014454.1$ & 27244 & SESN1 & 1.7 \\
\hline 2600463 & NM_003842.3 & 8795 & TNFRSF $10 B$ & 1.6 \\
\hline .5690554 & $N M=003620.2$ & 8493 & PPM1D & 1.6 \\
\hline .5420538 & NM 033285.2 & 94241 & TP53INP1 & 1.6 \\
\hline 5570678 & NM_015920.3 & 51065 & $R P S 27 L$ & 1.6 \\
\hline 3520092 & NM 138765.2 & 581 & $B A X$ & 1.6 \\
\hline 3520743 & NM 012396.3 & 23612 & PHLDA3 & 1.6 \\
\hline .4730711 & AK092074 & & HS. 193406 & 1.6 \\
\hline 670255 & NM_001924.2 & 1647 & GADD $45 A$ & 1.5 \\
\hline 4880673 & $N M=001924.2$ & 1647 & GADD $45 A$ & 1.5 \\
\hline 4280482 & $N M_{2}=018370.2$ & 55332 & $D R A M$ & 1.5 \\
\hline 650241 & $N M_{2} 016545.4$ & 5.1278 & IER5 & 1.5 \\
\hline 4480288 & $N M \_022767.2$ & 64782 & ISG2OL1 & 1.4 \\
\hline 4390300 & $N M_{2}=005749.2$ & 10140 & $T O B 1$ & 1.4 \\
\hline 2490215 & $N M_{-145263.2}$ & 132671 & SPATA18 & 1.4 \\
\hline 1010487 & NM 006763.2 & 7832 & BTG2 & 1.4 \\
\hline 3520020 & NM 001037333.1 & 26999 & CYFIP2 & 1.4 \\
\hline 4230196 & NM_002266.2 & 3838 & KPNA2 & 1.3 \\
\hline 5290475 & NM_078467.1 & 1026 & CDKN1A & 1.3 \\
\hline 6510553 & NM 005224.2 & 1820 & $A R I D 3 A$ & 1.2 \\
\hline 4480519 & NM_018217.1 & 55741 & EDEM2 & 1.2 \\
\hline 20471 & CD706077 & & HS.5721.21 & 1.2 \\
\hline 3940762 & AKQ57677 & & HS.532698 & 1.2 \\
\hline .6550327 & $N M=006502.1$ & 5429 & $\mathrm{POLH}$ & 1.2 \\
\hline 780168 & $N M \_213595.1$ & 23479 & ISCU & 1.2 \\
\hline 150095 & $N M=0010316852$ & 7159 & TP.53BP. 2 & 1.2 \\
\hline 3890300 & $N M \quad 018457.2$ & .54458 & $P R R 13$ & .1 .1 \\
\hline 1820615 & NM_018910.2 & 56141 & PCDHA7 & 1.1 \\
\hline 2710341 & NM_ 183079.2 & 5621 & $P R N P$ & 1.1 \\
\hline 1300762 & NM 018234.2 & 55240 & STEAP3 & 1.1 \\
\hline 6060358 & AW301107 & HS.541717 & & 1.0 \\
\hline 7320301 & NM 001295.2 & 1230 & $C C R 1$ & 0.9 \\
\hline 6590082 & AW183894 & F- & HS. 542993 & 0.9 \\
\hline .2510731 & $N M_{2} 018233.3$ & 55239 & OGFOD1 & 0.9 \\
\hline 2510731 & NM_018233.3 & 55239 & OGFOD 1 & 0.9 \\
\hline 1980768 & $N M_{2}=005067.5$ & 6478 & $\mathrm{SIAH} 2$ & 0.9 \\
\hline 2630739 & BX106991 & & HS. 154948 & 0.9 \\
\hline 450615 & $N M=005953.2$ & .4502 & $M T 2 A$ & 0.8 \\
\hline
\end{tabular}




\begin{tabular}{lcccc}
6020735 & NM_016095.1 & 51659 & GINS2 & $\mathbf{0 . 8}$ \\
2940142 & NM_033259.2 & 94032 & CAMK2N2 & $\mathbf{0 . 8}$ \\
\hline 770162 & NM_001006682.1 & 474343 & SPIN2B & 0.8 \\
\hline
\end{tabular}

*Transcripts of genes and particular transcriptional forms of IMR-32 cells that were responsive to treatment with $15 \mathrm{nM}$ doxorubicin for $24 \mathrm{~h}$ were shown, as compared to control cells (ANOVA at FDR $<5 \%$ ).**The fold change reflects the ratio of the values of signals from DOX-treated cells and control cells.
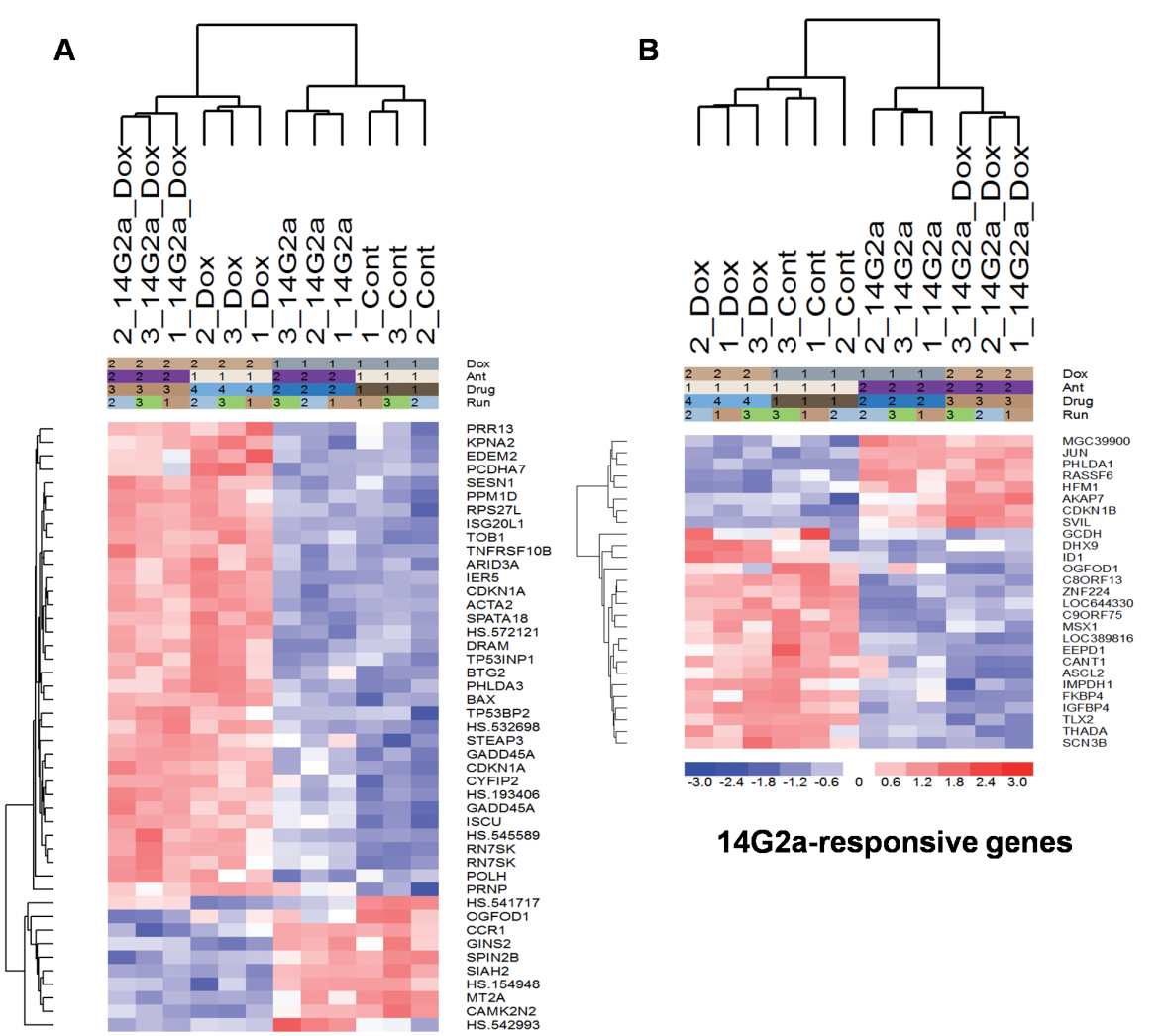

Figure 1. Hierarchal cluster analysis of genes affected by the tested drugs in the experimental groups of IMR-32 cells was performed with dChip software using Euclidean distance and average linkage method.

Genes and transcriptional forms responsive to (A) DOX $(15 \mathrm{nM}, 24 \mathrm{~h})$ and (B) $14 \mathrm{G} 2 \mathrm{a}(40 \mu \mathrm{g} / \mathrm{ml}, 24 \mathrm{~h})$ with ANOVA at FDR $<5 \%$ are shown. Intensity of the color is proportional to the fold change (see the bars below the images of the clusters).

from about 0.96 to 0.8 . The changes of expression of transcripts in the 14G2a-treated samples were even more restricted, when compared to control cells (Table 2). None of the transcripts were increased more than 1.5fold. The PHLDA1 gene expression was changed 1.4fold, followed by JUN (1.3-fold). Some transcripts were decreased below 0.8 -fold, including that of ID1, IGFBP4, MSX1, TLX2 and 3 sequences (C8ORF13, LOC389816, C9ORF7). Based on ontological classification analyses some genes were grouped according to their involvement into particular biological functions (see Table 3 for more details on gene ontology terms). Hence, some DOX-responsive genes were linked to: induction and positive regulation of cell death (including apoptosis), DNA metabolic processes, involvement in cell cycle, negative regulation of cell proliferation, and response to UV. On the contrary only one and unique gene ontology term was assigned to the 14G2a-responsive genes, i.e., regulation of RNA metabolic processes, as compared to the DOX-responsive genes. Based on the gathered data, we can conclude that although overall a restricted number of genes responded to the drugs tested in our model and changes of the most of the transcripts are limited, several interesting candidates can be selected for further analyses.

\section{RT-PCR and western blot analyses of selected doxorubicin-responsive genes}

In order to verify some changes of gene expression in the DOX-treated IMR-32 cells, we selected CDKN1A [cyclin-dependent kinase inhibitor 1A (p21, Cip1)], TNFRSF10B (tumor necrosis factor receptor superfamily, member 10B), RPS27L (ribosomal protein S27-like), SESN1 (sestrin 1), PPM1D (protein phosphatase, $\mathrm{Mg}^{2+} / \mathrm{Mn}^{2+}$ dependent, 1D) as examples of the genes that were up-regulated more than 1.5 -fold in the microarrays. We tested levels of their transcripts in IMR-32 cells treated with $15 \mathrm{nM}$ and 30 $\mathrm{nM}$ DOX for $24 \mathrm{~h}$ using semiquantitative RT-PCR (as 
Table 2. Transcripts responsive to treatment with the $14 \mathrm{G} 2 \mathrm{a}$ mAb*

\begin{tabular}{|c|c|c|c|c|}
\hline Probe ID & NCBI accession no. & Gene ID & Gene name & Fold change $e^{* *}$ \\
\hline 5900725 & $N M=007350.3$ & 22822 & PHLDA1 & 1.4 \\
\hline 6510367 & $N M_{2}=002228.3$ & 3725 & JUN & 1.3 \\
\hline 1030348 & $N M=004064.2$ & 1027 & CDKN1B & 1.2 \\
\hline 5340504 & NM_004842.2 & 9465 & $A K A P 7$ & 1.2 \\
\hline 70270 & NM_194324.1 & 286527 & MGC39900 & 1.2 \\
\hline 3140603 & NM_003174.3 & 6840 & SVIL & 1.2 \\
\hline 630240 & NM 177532.3 & 166824 & RASSFG & 1.2 \\
\hline 6250376 & NM_001017975.3 & 164045 & HFM1 & 1.1 \\
\hline 1580626 & NM_013398.1 & 7767 & ZNF224 & 0.9 \\
\hline 6660201 & $N M=000159.2$ & 2639 & $G C D H$ & 0.9 \\
\hline 2900379 & $N M=001357.3$ & 1660 & DHX9 & 0.9 \\
\hline 7200435 & $N M_{2}=005170.2$ & 430 & $A S C L 2$ & 0.9 \\
\hline 1580719 & $N M=022065.4$ & 63892 & THADA & 0.9 \\
\hline 2510731 & $N M_{2}=018233.3$ & 55239 & OGFOD1. & 0.9 \\
\hline 2510731 & $N M=018233,3$ & 55239 & OGFOD1 & 0.9 \\
\hline 3120431 & NM_000883.2 & 3614 & IMPDH1 & 0.9 \\
\hline 5860358 & NM 138793,2 & 124583 & CANT1 & 0.8 \\
\hline 50286 & NM_030636.2 & 80820 & EEPD1 & 0.8 \\
\hline 6180402 & XR_017492.1 & 644330 & LOC644330 & 0.8 \\
\hline 7380348 & NM_018400.3 & 55800 & $S C N 3 B$ & 0.8 \\
\hline 2100750 & NM_002014,2 & 2288 & FKBPA & 0.8 \\
\hline 670386 & $N M_{=}=181353.1$ & 3397 & ID1 & 0.8 \\
\hline 4010184 & $N M_{2} 053279.1 \ldots$ & 83648 & C8ORF13 & 0.8 \\
\hline 2140541 & NM_001013653.1 & 389816 & LOC389816 & 0.7 \\
\hline 7510414 & $N M=001552.2$ & 3487 & IGFBPA & 0.7 \\
\hline 1010333 & NM_O002448.3 & 4487 & $M S X 1$ & 0.7 \\
\hline 1440050 & $N M=173691.2$ & .286262 & C9ORF75 & 0.7 \\
\hline 6100370 & NM_016170.3 & 3196 & $T L X 2$ & 0.7 \\
\hline
\end{tabular}

*Transcripts of genes and particular transcriptional forms of IMR-32 cells that were responsive to treatment with the $14 \mathrm{G} 2 \mathrm{a} \mathrm{mAb}$ (40 mg/ml) for $24 \mathrm{~h}$ were shown, as compared to control cells (ANOVA at FDR $<5 \%$ ). **The fold change reflects the ratio of the values of signals from $14 \mathrm{G} 2 \mathrm{a}-$ treated cells and control cells.

compared to normal cells). The transcript of $A C T B$ was also measured in the samples and used for signal normalization. For all 5 aforementioned transcripts we observed an increase in signal intensity for the samples of RNA isolated from IMR-32 cells treated with 30 nM DOX for $24 \mathrm{~h}$, while the changes in the samples of RNA from cells treated with $15 \mathrm{nM}$ DOX were rather small and not always conclusive (see Fig. 2 A, B). Then, for SESN1, PPM1D, and RPS27L, we analyzed levels of transcripts for five time points, i.e., 8, $16,24,32,48 \mathrm{~h}$ using samples of RNA isolated from IMR-32 cells treated with $30 \mathrm{nM}$ DOX, as compared to control cells (see Fig. 2C). For the transcript of SESN1 an increase was clearly observed for all time points tested, while expression of the other two genes was consistently up-regulated from 24 h. Additionally, a western blot technique was applied to measure levels of proteins in the samples from IMR-32 cells treated with $15 \mathrm{nM}$ and $30 \mathrm{nM}$ DOX for $24 \mathrm{~h}$, as compared to control cells. Signals from detection of GAPDH were used for protein normalization in the samples (Fig. 3). Only for RPS27L, we could observe increase in the protein levels for both concentration of DOX used (Fig. 3A). A level of PPM1D was increased only in samples treated with $15 \mathrm{nM}$ DOX (Fig. 3C), while it was decreased along with sestrin 1 in samples treated with $30 \mathrm{nM}$ DOX (Fig. 3B,C, pairwise t tests between controls and DOX-treated samples did not show statistical significance of the measured changes of levels of RPS27L, PPM1D, and sestrin 1). Based on the results of the experiments, we could confirm that DOX increased expression of transcripts of the five selected genes. However, additional experiments (e.g., performed for longer time points of incubation of cells with DOX) are necessary to establish effects of DOX on the expression of the genes on the protein levels. 
Table 3. Examples of gene ontology (GO) terms for the list of DOX- and 14G2A-responsive genes*

\begin{tabular}{|c|c|c|}
\hline GO term & $\begin{array}{l}\text { Number } \\
\text { of genes }\end{array}$ & Genes \\
\hline \multicolumn{3}{|l|}{ DOX-responsive genes } \\
\hline $\begin{array}{l}\text { GO:0012502 } \\
\text { induction of programmed cell death }\end{array}$ & 7 & $\begin{array}{l}\text { CDKN1A, TNFRSF10B, TP53BP2, BAX,RPS27L, PHLDA3, } \\
\text { TP53INP1 }\end{array}$ \\
\hline $\begin{array}{l}\text { GO:0043067 } \\
\text { regulation of programmed cell death }\end{array}$ & 9 & $\begin{array}{l}\text { CDKN1A, TNFRSF10B, BTG2, TP53BP2, BAX, RPS27L, PRNP, } \\
\text { PHLDA3, TP53INP1 }\end{array}$ \\
\hline $\begin{array}{l}\text { GO:0043068 } \\
\text { positive regulation of programmed cell death }\end{array}$ & 7 & $\begin{array}{l}\text { CDKN1A, TNFRSF10B, TP53BP2, BAX, RPS27L, PHLDA3, } \\
\text { TP53INP1 }\end{array}$ \\
\hline $\begin{array}{l}\text { GO:0006259 } \\
\text { DNA metabolic process }\end{array}$ & 7 & GINS2, POLH, BTG2, BAX, RPS27L, KPNA2, GADD45A \\
\hline $\begin{array}{l}\text { GO: } 0008285 \\
\text { negative regulation of cell proliferation }\end{array}$ & 6 & CDKN1A, PPM1D, BTG2, BAX, SESN1, TOB1 \\
\hline $\begin{array}{l}\text { GO:0000086 } \\
\text { G2/M transition of mitotic cell cycle }\end{array}$ & 3 & CDKN1A, PPM1D, GADD45A \\
\hline $\begin{array}{l}\text { GO:0051329 } \\
\text { interphase of mitotic cell cycle }\end{array}$ & 4 & CDKN1A, PPM1D, KPNA2, GADD45A \\
\hline $\begin{array}{l}\text { GO:0009411 } \\
\text { response to UV }\end{array}$ & 3 & CDKN1A, POLH, BAX \\
\hline \multicolumn{3}{|l|}{ 14G2a-responsive genes } \\
\hline $\begin{array}{l}\text { GO:0051252 } \\
\text { regulation of RNA metabolic process }\end{array}$ & 8 & ASCL2, DHX9, CDKN1B, MSX1, ID1, ZNF224, JUN, TLX2 \\
\hline
\end{tabular}

${ }^{*} P<0.01$, Fisher's exact test

A

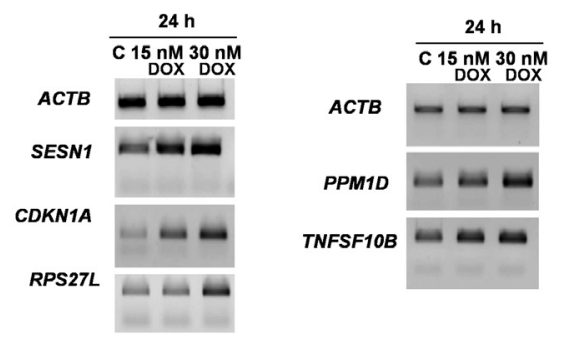

C

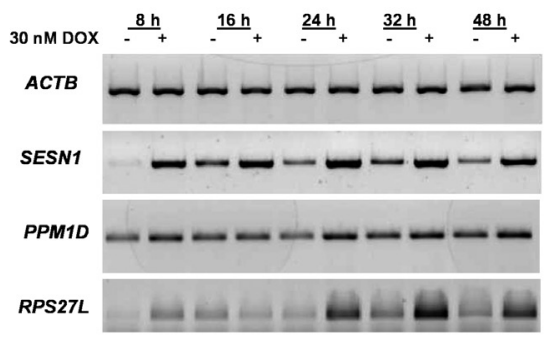

Figure 2. Effects of doxorubicin ( $15 \mathrm{nM}$ and $30 \mathrm{nM}$ ) on expression of transcripts of selected responsive genes.

RT-PCR was used to measure effects of doxorubicin (15 nM and 30 $\mathrm{nM}$ ) on transcripts of SESN1, CDKN1A, RPS27L, PPM1D, and TNFSF10B in the cell cultures of IMR-32 after $24 \mathrm{~h}$ (A, B), while transcripts of SESN1, RPS27L, PPM1D were also verified after addition of $30 \mathrm{nM}$ DOX for 8, 16, 24, 32, $48 \mathrm{~h}$ (C). ACTB gene expression was used as a reference. Products of RT-PCR were resolved with agarose gel electrophoresis (one of three independent experiments is shown).

\section{Qt-RT-PCR analyses of selected 14G2a-responsive genes}

Previously, we reported that in IMR-32 cells treated with 14G2a both transcript and protein levels of the PHLDA1 gene (pleckstrin homology-like domain, family A, member 1) were statistically meaningfully increased (Horwacik et al., 2013). In order to verify some additional changes of transcripts in the 14G2a-treated IMR-32 cells, we selected 3 genes that were up-regulated, i.e., JUN (jun oncogene), SVIL (supervillin), RASSF6 (Ras association
A
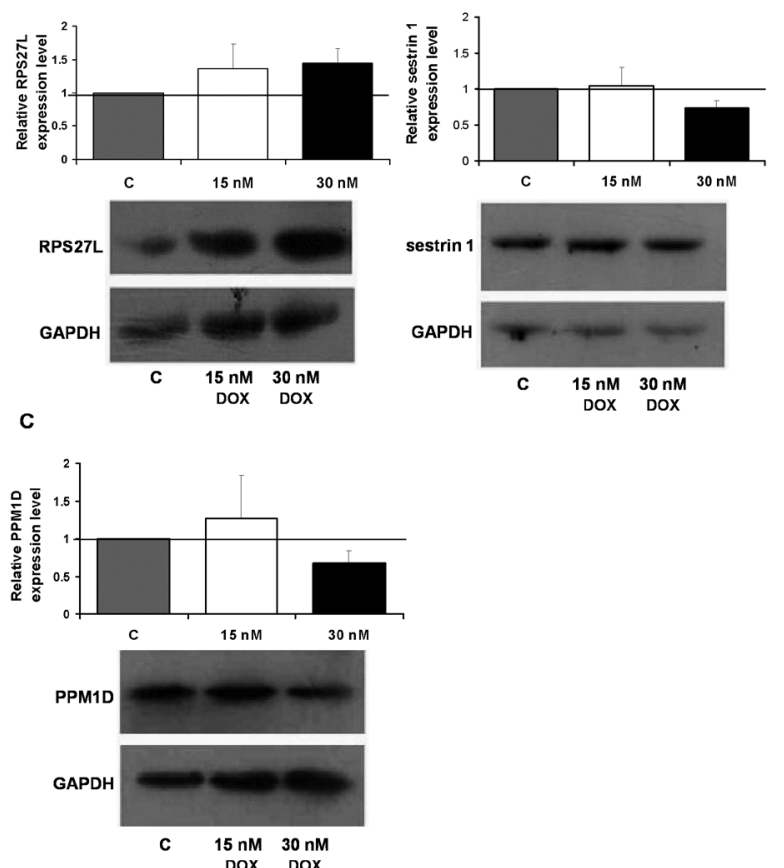

Figure 3. Effects of doxorubicin ( $15 \mathrm{nM}$ and $30 \mathrm{nM}$ ) on expression of proteins of selected responsive genes.

Levels of RPS27L (A), sestrin 1 (B), and PPM1D (C) were measured in the cell cultures of IMR-32 $24 \mathrm{~h}$ after addition of the drug with western blot. GAPDH protein expression was used as a reference (one of three independent experiments was shown). Data on the graphs are presented as means from three independent experiments $( \pm$ SEM) and calculated versus control values, set as 1 (black baseline). $T$ tests (control samples vs. treated samples) did not show statistical significance.

(RalGDS/AF-6) domain family member 6) and 2 genes that were down-regulated in the microarray analysis, i.e., ID1 (inhibitor of DNA binding 1, dominant negative helix-loop-helix protein) and TLX2 (thyroid adenoma associated). Also, we measured levels of the CDKN1A gene in the cells. Qt-RT-PCR was applied to quantify levels 

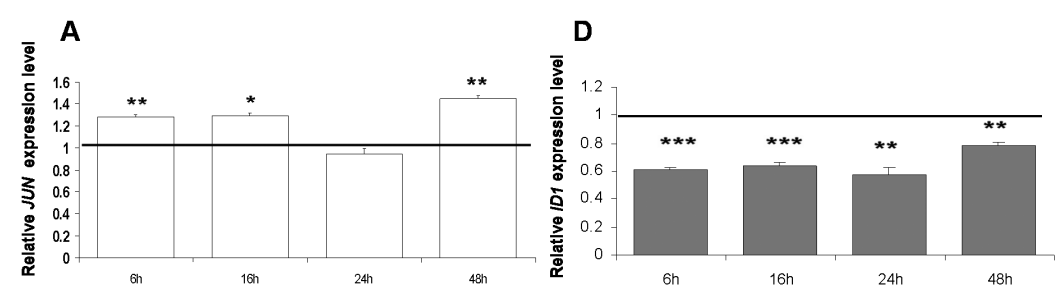

B

E
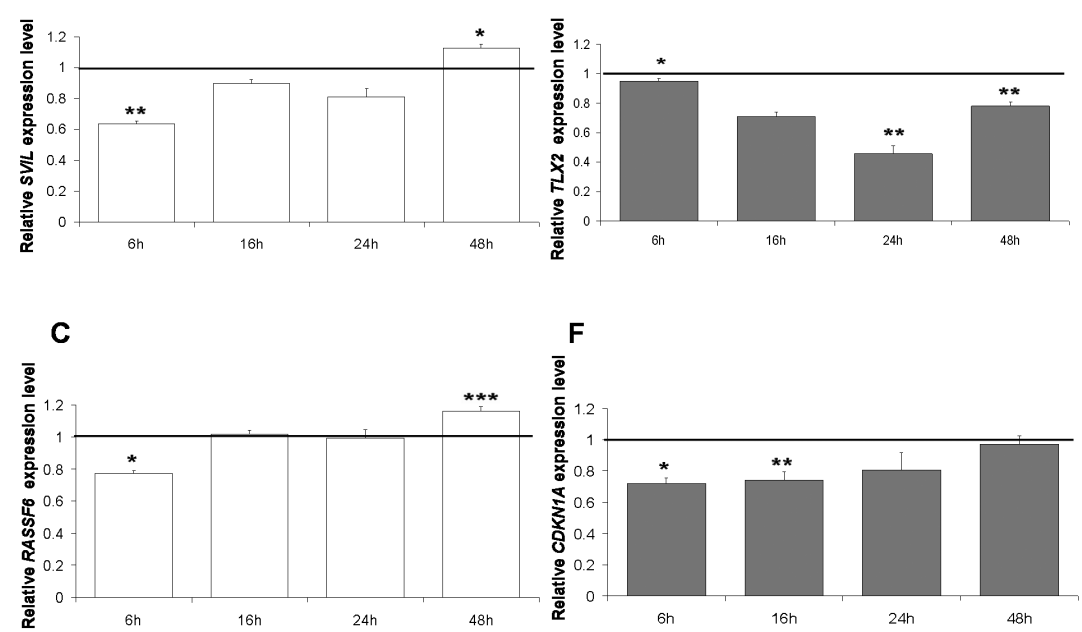

Figure 4. Qt-RT-PCR analysis showing relative mRNA levels of selected genes in IMR-32 cells upon 6, 16, 24 and 48 hours of $14 \mathrm{G} 2 \mathrm{a}$ $\mathrm{mAb}$ treatment $(40 \mu \mathrm{g} / \mathrm{ml})$.

JUN (A), SVIL (B), RASSF6 (C), ID1 (D), TLX2 (E), CDKN1A (F). EF-2 CDNA was used as a reference. Data are presented as means of triplicates from four to five independent experiments ( \pm SEM) and calculated versus control values, set as 1 (black baseline). ANOVA shows statistically significant changes of all levels of gene expression in time in IMR-32 cells. $P$-values for $t$ test (control samples vs. treated samples) were as follows: $P<0.05\left({ }^{*}\right), P<0.01\left({ }^{* *}\right), P<0.001(* * *)$.

of the transcripts in IMR-32 cells treated with $40 \mu \mathrm{g} /$ $\mathrm{ml}$ of $14 \mathrm{G} 2 \mathrm{a}$ for $6,16,24,48 \mathrm{~h}$ (Fig. $4 \mathrm{~A}-\mathrm{F}$ ). The transcript of EF2 was used for signal normalization in the samples. The transcript of JUN was statistically significantly up-regulated in RNA samples of IMR-cells incubated with the 14G2a mAb for 6, 16, $48 \mathrm{~h}(P<0.05$, for pairwise $\mathrm{t}$ tests between the control and treated samples). The transcripts of SVIL and RASSF6 were increased only for $48 \mathrm{~h}(P<0.05$, for pairwise $\mathrm{t}$ tests between the control and treated samples), while for the time point of $6 \mathrm{~h}$ both transcripts were down-regulated $(P<0.05$, for pairwise $t$ tests between the control and treated samples). The transcripts of ID1 and TLX2 were shown to be down-regulated for all 4 time points tested (for most of the time points evaluated $P<0.05$ was calculated using pairwise $\mathrm{t}$ tests between the control and treated samples). Additionally, we showed that the transcript of CDKN1 $A$ was statistically significantly decreased upon the treatment with the $14 \mathrm{G} 2 \mathrm{a} \mathrm{mAb}$ for 6 and $16 \mathrm{~h}$. The data gathered allowed us to conclude that qt-RT-PCR results confirmed decrease of the transcripts for ID1 and TLX2 shown by the microarrays. The increase of the transcript of JUN was shown for $6,16,48 \mathrm{~h}$, but not for $24 \mathrm{~h}$ as reported in the microarray experiments. Additionally, meaningful opposite effects, i.e., a decrease for the $6 \mathrm{~h}$ time point and an increase for the $48 \mathrm{~h}$ time point, were observed for the transcripts of SVIL and RASSF6. Finally, although direct comparison of changes in the transcript of CDKN1A were not performed for DOX- and 14G2a-treated cells contrasting effects can be observed (Fig. 2 and Fig. 4), which require verification by side-by side sample analysis.

\section{Effects of doxorubicin, topotecan and the 14G2a mAb on expression of NDUFAF2 and MYCN}

We have previously shown that the increase of transcript and protein of PHLDA1 in 14G2a-treated IMR32 cells is correlated with a decrease of two oncogenic proteins i.e., aurora A (in whole cell extracts) and MYCN (in cytoplasmic and nuclear fractions) (Horwacik et al., 2013). Also, cytotoxicity induced with 14G2a in IMR-32 cells was accompanied by rise in activity of caspases 3 and 7 (Horwacik et al., 2013; Kowalczyk et al., 2009). Thus, we extended our research to correlate levels of MYCN and a novel NDUFAF2 [(NADH dehydrogenase (ubiquinone) complex I, assembly factor 2)] gene encoding for a mimitin protein (MYC-induced mitochondrial protein). We treated IMR-32 cells with two cytotoxic drugs, DOX and TPT, which are used for neuroblastoma treatment in clinics and were previously shown by us to act synergistically with 14G2a on IMR32 cells (Kowalczyk et al., 2009). Again cells treated with the $14 \mathrm{G} 2 \mathrm{a} \mathrm{mAb}$ were included. We showed that MYCN and mimitin are expressed in IMR-32 and KELLY (both $M Y C N$-amplified) neuroblastoma cell lines, contrasting to a SK-N-SH (a MYCN-non-amplified) neuroblastoma cell line, in which no MYCN was detected and lower intensity of the band of mimitin was measured (Fig. $5 \mathrm{~A})$. Also, in IMR-32 we confirmed that no MYC protein was detected (there was no MYC transcript as well, data not shown). To compare cytotoxic effects of DOX and TPT on expression of the genes, we selected concentration of $17 \mathrm{nM}$ DOX and $2 \mathrm{nM}$ TPT that caused reduction of cell viability to about $70 \%$ of control cells after $48 \mathrm{~h}$ (measured by a MT'T test, data not shown). 
A

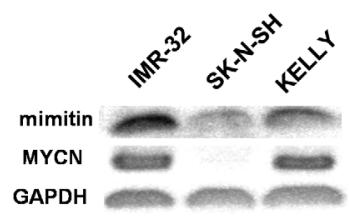

C

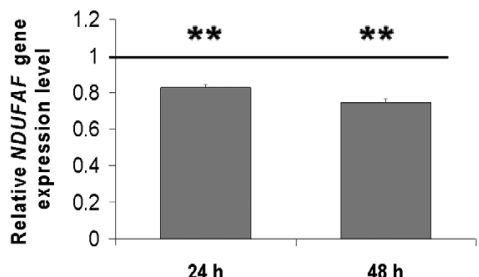

$24 \mathrm{~h}$

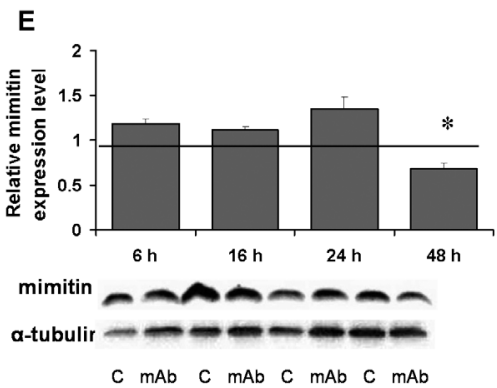

B

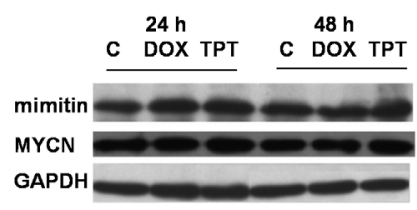

D

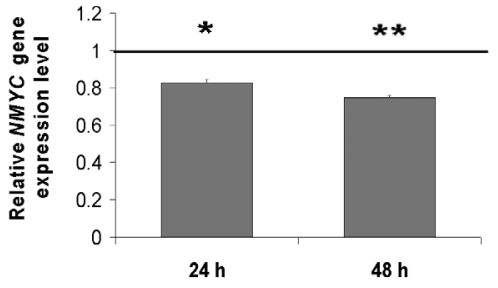

$\mathbf{F}$

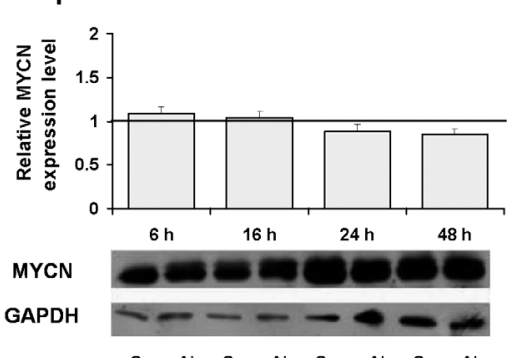

c mAb C mAb C mAb C mAb

Figure 5. Effects of DOX, TPT and the 14G2a mAb on expression of NDUFAF2 and MYCN were analyzed in IMR-32 cells.

(A) Western blot analysis of mimitin and MYCN protein levels in MYCN-amplified IMR-32, KELLY cells and MYCN-non-amplified SK-N-SH cells. (B) Expression of mimitin and MYCN in IMR-32 cells treated with $17 \mathrm{nM}$ DOX and $2 \mathrm{nM}$ TPT for 24 and $48 \mathrm{~h}$ (one experiment is shown). Qt-RT-PCR was used to measure levels of NDUFAF2 (C) and MYCN (D) 24 and $48 \mathrm{~h}$ after treatment with $14 \mathrm{G} 2 \mathrm{a}(40 \mu \mathrm{g} / \mathrm{ml})$. The transcript of E2F was measured as a reference. Data are presented as means of triplicates from three independent experiments ( \pm SEM) and calculated versus control values, set as 1 (black baseline). ANOVA shows statistically significant changes of MYCN expression levels in time in IMR-32 cells and no statistically significant changes of NDUFAF2 expression levels in time. P-values for t test (control samples vs. treated samples) were $P<0.05(*), P<0.01(* *)$. Changes in mimitin (E) and MYCN (F) expression in IMR-32 cells after treatment with 40 $\mu \mathrm{g} / \mathrm{ml}$ of $14 \mathrm{G} 2 \mathrm{a}$ for $6,16,24,48 \mathrm{~h}$ ( $\alpha$-tubulin or GAPDH expression was measured as a reference for western blot analyses). Data on the graphs are presented as means from three independent experiments ( \pm SEM) and calculated versus control values, set as 1 (black baseline). $P$-value for $t$ test (control samples vs. treated samples) is $P<0.05(*)$.

Western blot analysis of levels of mimitin and MYCN in DOX- and TPT-treated IMR-32 cells did not reveal their considerable changes (Fig. 5B, a result from a single experiment is shown). However, when we analyzed expression of the transcripts of NDUFAF2 and MYCN by qt-RT-PCR in the 14G2a-treated cells, we measured a statistically meaningful decrease in the levels of both transcripts (Fig. 5C, D). Furthermore, we used western blot to show that a decrease in the level of MYCN is correlated with a decrease of the level of mimitin in whole cell extracts from the 14G2a-treated IMR-32 cells at 24 and $48 \mathrm{~h}(P<0.05$, for mimitin by a t test, controls vs. 14G2a-treated samples for 48 h, Fig. 5E, F).

\section{DISCUSSION}

Gene expression signatures of tumor cells are extensively studied to better understand differences between transformed and normal cells, but also in quest for diagnostic, or prognostic markers, and new targets for treatment of patients with cancer. Thus, we aimed to gain more insight into changes of transcriptome of IMR-32 cells treated with 14G2a and to compare the effects induced with the antibody and doxorubicin. In general, only minor changes in levels of the analyzed transcripts were observed between control, untreated cells, and
14G2a-treated cells in our whole-genome transcriptome studies, suggesting that in the next step we should focus on detailed proteome analyses. However, it should be stressed that the experiments allowed to find correlations between 14G2a and genes important for neuroblastoma biology. For instance, ID1 and TLX2 were downregulated in the arrays and in the following qt-RT-PCR analyses. TLX2 and PHOX2B are transcription factors important for differentiation of autonomic nerve cells (Borghini et al., 2006). Also, ID-1,-2, and -3 proteins are involved in keeping neuroblastoma cells in undifferentiated state as shown by Jögi and colleagues (Jögi et al., 2002).

Based on the GO analysis, the 2 aforementioned genes and 6 others (ASCL2, DHX9, CDKN1B, MSX1, ZNF224, JUN) are involved in regulation of RNA metabolic processes (GO: 0051252). Literature search allowed us to establish that ASCL2, a transcription factor protein involved in WNT signaling and miR-200s participate in regulation of transitions between mesenchymal and epithelial phenotypes (Tian et al., 2014). Also, MSX1, yet another transcription factor, was shown to be involved in Delta-Notch and WNT signaling in neuroblastoma (Revet et al., 2008; Revet et al., 2010). Recently, Chen and colleagues, showed that DHX9 (RNA helicase A) and its nuclear localization is involved in pro-apoptotic function of $\mathrm{KIF} 1 \mathrm{~B} \beta$, a protein with tumor-suppressor properties 
that is encoded in a region 1p36.2 lost in a subset of neuroblastomas (Chen et al., 2014). Moreover, DHX9 was among ten genes with recurrent gene mutations that correlated with pathways deregulation and clinical outcomes among patients with lung adenocarcinoma who never-smoked (Sun et al., 2014). Finally, ZNF224 was implicated in apoptosis induced after DNA damage in leukemia cells (Montano et al., 2013).

Two genes, SVIL and RASSFG showed a decrease in expression for the $6 \mathrm{~h}$ time point and an increase of expression for the $48 \mathrm{~h}$ time point in samples of 14G2a-treated IMR-32 cell, thus stressing the need for detailed analyses of the 14G2a-responsive genes yielded by microarrays. They are necessary to verify the results generated with the whole genome analysis approach. Additionally, analysis of both mRNA and protein levels in samples collected for additional time points or other 14G2a-sensitive neuroblastoma cell lines are warranted to elucidate roles of the selected genes in our model. Of interest to us is a report on a role of RASSF6 as a tumor suppressor and its function in P21 accumulation, induction of G1 cell cycle arrest, and apoptosis in clear cell renal cell carcinoma (Liang et al., 2014).

Previously we reported that the PHLDA1 transcript and protein levels were up-regulated in our model. Also, the P53 protein was up-regulated in the IMR-32 cells treated with $14 \mathrm{G} 2 \mathrm{a}$ from $2 \mathrm{~h}$ and its nuclear accumulation was shown from $6 \mathrm{~h}$ (Horwacik et al., 2013). Both proteins are involved in interactions with aurora A (Johnson et al., 2011). The total level of the oncogenic protein and the extent of its phosphorylation at Thr288 were decreased in the 14G2a-treated IMR-32 and LA-N1 cells (Horwacik et al., 2013). In addition, in the microarrays data the transcript of SCN3B, a P53 inducible gene, (Adachi et al., 2004) was down-regulated in the 14G2a-treated cells. Again, this highlights the need for analysis of samples collected at additional time points. Also, the transcript of FKBP4 (FKBP54) encoding a chaperone protein (Shim et al., 2009) was decreased in the microarrays. This adds to our previous findings that HSP40 and HSP70 proteins were decreased in IMR-32 cells treated with 14G2a (Horwacik et al., 2013). Thus, we can conclude that the data from the microarray and the qt-RT-PCR analyses of transcriptome of IMR-32 cells after 14G2a extend our knowledge on mechanism of action of the antibody on the cell line.

Yet another transcription factor, MYCN, was decreased in cytoplasmic and nuclear extracts of IMR-32 cells after 14G2a treatment (Horwacik et al., 2013). Here, we add data from qt-RT-PCR showing that down-regulation of MYCN mRNA correlates with decreased levels of the protein in whole cell extracts of IMR-32 after the $\mathrm{mAb}$ addition. Interestingly, mRNA and protein levels of NDUFAF2 are also down-regulated in IMR-32 cells treated with 14G2a. The novel NDUFAF2 gene encoding for mimitin was shown to be directly stimulated by MYC and involved in proliferation of esophageal squamous cell carcinoma (Tsuneoka et al., 2005). Its functions are still elucidated. The mimitin protein was showed to act as a molecular chaperone for mitochondrial complex I assembly (Ogilvie et al., 2005). On the other hand, in 2013 Schlehe and colleagues showed that the protein deficiency reduced complex-1 activity, increased levels of oxidative stress and deletion of mitochondrial DNA, but was dispensable for maturation of the complex (Schlehe et al., 2013). Moreover, over-expression of mimitin was reported to indirectly correlate with reduction of activity of caspase 3/7 in HepG2 cells (Wegrzyn et al., 2009). In our model, the observed reduction of mimitin protein correlates with our previous report on a rise in caspase $3 / 7$ activity at $48 \mathrm{~h}$ and $72 \mathrm{~h}$ of IMR-32 treatment with 14G2a (Horwacik et al., 2013). This may indicate a role of mimitin in observed apoptosis and encourages further research on the involvement of the protein in our model. Finally, as no MYC is expressed in MYCN-amplified IMR-32 neuroblastoma cells and the levels of both MYCN and mimitin are reduced in the 14G2a-treated IMR-32 cells, it might be of interest to further investigate whether the transcription factor is directly involved in regulation of expression of the NDUFAF2 gene. Recently, Murphy and colleagues showed that in neuroblastoma cell lines MYCN binds more selectively to the CATGTG motif than to the classic E-box CACGTG motif. Also, other motifs, i.e., CATT'TG, CATCTG, CAACTG were bound by MYCN in MYCN-amplified cells. (Murphy et al., 2009). On that note, possible role of MYCN in the NDUFAF2 gene expression could be investigated.

To summarize, based on the reported data from our experiments we gained more insight into effects of 14G2a on IMR-32 neuroblastoma cells and selected new and interesting genes for further investigation.

\section{Acknowledgements}

We thank Dr. R. Reisfeld for providing us with the hybridoma cell line producing $14 \mathrm{G} 2 \mathrm{a}$ mAb. Faculty of Biochemistry, Biophysics and Biotechnology is a partner of the Leading National Research Center (KNOW) supported by the Ministry of Science and Higher Education.

This work was supported mainly by the grant N301 158635 from the Ministry of Science and Higher Education and partially by the grants MTKD-2006-042586 (ACUP) from the European Commission, 63/6 PR UE/2007/7 from the Ministry of Science and Higher Education, NCN-2012/07/B/NZ1/02808 from the Polish National Science Center, and DS/8/WBBiB UJ.

\section{Conflict of interest}

The authors declare that they have no conflict of interest.

\section{REFERENCES}

Adachi K, Toyota M, Sasaki Y, Yamashita T, Ishida S, Ohe-Toyota M, Maruyama R, Hinoda Y, Saito T, Imai K, Kudo R, Tokino T (2004) Identification of SCN3B as a novel p53-inducible proapoptotic gene. Oncogene 23: 7791-7798.

Borghini S, Bachetti T, Fava M, Di Duca M, Cargnin F, Fornasari D, Ravazzolo R, Ceccherini I (2006) The TLX2 homeobox gene is a transcriptional target of PHOX2B in neural-crest-derived cells. Biochem J 395: 355-361.

Brodeur GM, Bagatell R (2014) Mechanisms of neuroblastoma regression. Nat Rev Clin Oncol 11: 704-713.

Chen ZX, Wallis K, Fell SM, Sobrado VR, Hemmer MC, Ramsköld D, Hellman U, Sandberg R, Kenchappa RS, Martinson T, Johnsen JI, Kogner P, Schlisio S (2014) RNA helicase A is a downstream mediator of KIF1B $\beta$ tumor-suppressor function in neuroblastoma. Cancer Discov 4: 434-451.

Horwacik I, Durbas M, Boratyn E, Węrzyn P, Rokita H (2013) Targeting GD2 ganglioside and aurora A kinase as a dual strategy leading to cell death in cultures of human neuroblastoma cells. Cancer Lett 341: 248-264.

Horwacik I, Rokita H (2015) Targeting of tumor-associated gangliosides with antibodies affects signaling pathways and leads to cell death including apoptosis. Apoptosis 20: 679-688.

Jögi A, Persson P, Grynfeld A, Påhlman S, Axelson H (2002) Modulation of basic helix-loop-helix transcription complex formation by Id proteins during neuronal differentiation. J Biol Chem 277: 9118-9126.

Johnson EO, Chang KH, de Pablo Y, Ghosh S, Mehta R, Badve S, Shah K (2011) PHLDA1 is a crucial negative regulator and effector of Aurora A kinase in breast cancer. J Cell Sci 124: 2711-2722. 
Koressaar T, Remm M (2007) Enhancements and modifications of primer design program Primer3. Bioinformatics 23: 1289-1291.

Kowalczyk A, Gil M, Horwacik I, Odrowaz Z, Kozbor D, Rokita H (2009) The GD2-specific 14G2a monoclonal antibody induces apoptosis and enhances cytotoxicity of chemotherapeutic drugs in IMR-32 human neuroblastoma cells. Cancer Lett 281: 171-182.

Kowalczyk A, Guzik K, Slezak K, Dziedzic J, Rokita H (2005) Heat shock protein and heat shock factor 1 expression and localization in vaccinia virus infected human monocyte derived macrophages. $J$ Inflamm (Lond) 2: 12.

Liang YY, Zheng LS, Wu YZ, Peng LX, Cao Y, Cao X, Xie P, Huang BJ, Qian CN (2014) RASSF6 promotes p21(Cip1/Waf1)-dependent cell cycle arrest and apoptosis through activation of the JNK/SAPK pathway in clear cell renal cell carcinoma. Cell Cycle 13: 1440-1449.

Montano G, Cesaro E, Fattore L, Vidovic K, Palladino C, Crescitelli R, Izzo P, Turco MC, Costanzo P (2013) Role of WT1-ZNF224 interaction in the expression of apoptosis-regulating genes. Hum Mol Genet 22: 1771-1782.

Moreno L, Marshall LV, Pearson AD (2013) At the frontier of progress for paediatric oncology: the neuroblastoma paradigm. $\mathrm{Br} \mathrm{Med}$ Bull 108: 173-188.

Murphy DM, Buckley PG, Bryan K, Das S, Alcock L, Foley NH, Prenter S, Bray I, Watters KM, Higgins D, Stallings RL (2009) Global MYCN transcription factor binding analysis in neuroblastoma reveals association with distinct E-box motifs and regions of DNA hypermethylation. PLoS One 4: e8154.

Ogilvie I, Kennaway NG, Shoubridge EA (2005) A molecular chaperone for mitochondrial complex I assembly is mutated in a progressive encephalopathy. J Clin Invest 115: 2784-2792.

Øra I, Eggert A (2011) Progress in treatment and risk stratification of neuroblastoma: impact on future clinical and basic research. Semin Cancer Biol 21: 217-128.

Ramani P, Nash R, Rogers CA (2015) Aurora kinase A is superior to $\mathrm{Ki} 67$ as a prognostic indicator of survival in neuroblastoma. Histopathology 66: 370-379.

Revet I, Huizenga G, Chan A, Koster J, Volckmann R, van Sluis P, Øra I, Versteeg R, Geerts D (2008) The MSX1 homeobox transcription factor is a downstream target of PHOX2B and activates the Delta-Notch pathway in neuroblastoma. Exp Cell Res 314: 707719.

Revet I, Huizenga G, Koster J, Volckmann R, van Sluis P, Versteeg R, Geerts D (2010) MSX1 induces the Wnt pathway antagonist genes DKK1, DKK2, DKK3, and SFRP1 in neuroblastoma cells, but does not block Wnt3 and Wnt5A signalling to DVL3. Cancer Lett 289: 195-207.

Schlehe JS, Journel MS, Taylor KP, Amodeo KD, LaVoie MJ (2013) The mitochondrial disease associated protein Ndufaf2 is dispensable for Complex-1 assembly but critical for the regulation of oxidative stress. Neurobiol Dis 58: 57-67.

Shim S, Yuan JP, Kim JY, Zeng W, Huang G, Milshteyn A, Kern D, Muallem S, Ming GL, Worley PF (2009) Peptidyl-prolyl isomerase FKBP52 controls chemotropic guidance of neuronal growth cones via regulation of TRPC1 channel opening. Neuron 64: 471-483.

Skalniak A, Boratyn E, Tyrkalska SD, Horwacik I, Durbas M, Lastowska M, Jura J, Rokita H (2014) Expression of the monocyte chemotactic protein-1-induced protein 1 decreases human neuroblastoma cell survival. Oncol Rep 31: 2385-2392.

Stock C, Bozsaky E, Watzinger F, Poetschger U, Orel L, Lion T, Kowalska A, Ambros PF (2008) Genes proximal and distal to MYCN are highly expressed in human neuroblastoma as visualized by comparative expressed sequence hybridization. Am J Pathol 172: 203-214.

Sun Z, Wang L, Eckloff BW, Deng B, Wang Y, Wampfler JA, Jang J, Wieben ED, Jen J, You M, Yang P (2014) Conserved recurrent gene mutations correlate with pathway deregulation and clinical outcomes of lung adenocarcinoma in never-smokers. BMC Med Genomics 7: 32 .

Tian Y, Pan Q, Shang Y, Zhu R, Ye J, Liu Y, Zhong X, Li S, He Y, Chen L, Zhao J, Chen W, Peng Z, Wang R (2014) MicroRNA-200 (miR-200) cluster regulation by achaete scute-like 2 (Ascl2): impact on the epithelial-mesenchymal transition in colon cancer cells. J Biol Chem 289: 36101-36115.

Tsuneoka M, Teye K, Arima N, Soejima M, Otera H, Ohashi K, Koga Y, Fujita H, Shirouzu K, Kimura H, Koda Y (2005) A novel Myctarget gene, mimitin, that is involved in cell proliferation of esophageal squamous cell carcinoma. J Biol Chem 280: 19977-19985.

Untergrasser A, Cutcutache I, Koressaar T, Ye J, Faircloth BC, Remm M, Rozen SG (2012) Primer3 - new capabilities and interfaces. Nucleic Acids Research 40: e115.

Wang J, Wang H, Li Z, Wu Q, Lathia JD, McLendon RE, Hjelmeland $\mathrm{AB}$, Rich JN (2008) c-Myc is required for maintenance of glioma cancer stem cells. PLoS One 3: e3769.

Wegrzyn P, Yarwood SJ, Fiegler N, Bzowska M, Koj A, Mizgalska D, Malicki S, Pajak M, Kasza A, Kachamakova-Trojanowska N, Bereta J, Jura J, Jura J (2009) Mimitin — a novel cytokine-regulated mitochondrial protein. BMC Cell Biol 10: 23.

Yu AL, Gilman AL, Ozkaynak MF, London WB, Kreissman SG, Chen HX, Smith M, Anderson B, Villablanca JG, Matthay KK, Shimada H, Grupp SA, Seeger R, Reynolds CP, Buxton A, Reisfeld RA, Gillies SD, Cohn SL, Maris JM, Sondel PM; Children's Oncology Group (2010) Anti-GD2 antibody with GM-CSF, interleukin-2, and isotretinoin for neuroblastoma. N Engl J Med 363: 1324-1334. 